\title{
Can we predict the response to cyclosporine?
}
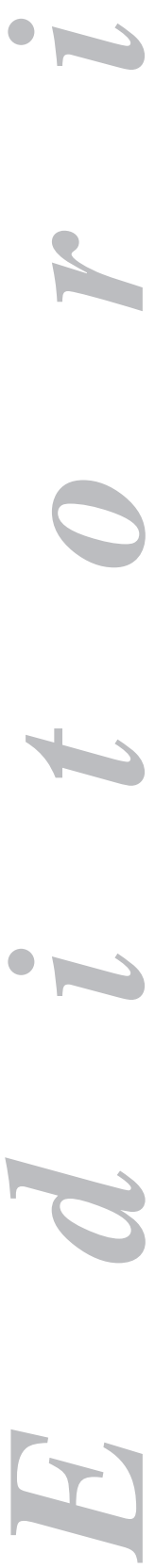

Ulcerative colitis (UC) is a chronic disease characterized by activity and remission episodes. Medical treatment is adjusted according to flare severity and disease extent. Approximately 15\% of patients have severe flares, defined as more than 6-10 bloody stools/day with fever, tachycardia, malaise, and/or increased C-reactive protein (CRP) levels (1-3). This condition requires hospitalization and, once other colitis causes -most particularly those infectious in origin-are ruled out, intravenous corticoids, with a variable response rate of around 60\%. Patients not responding within 3-5 days to this regimen with steroids in adequate doses are eligible for rescue therapy with some of the following options: intravenous cyclosporine (CyA), infliximab, or surgery (proctocolectomy) $(2,3)$. Choosing between these three options represents a medico-surgical decision based on clinical signs, radiographic and endoscopic findings, and biological parameters such as CRP and albumin. However, shorter time intervals when selecting therapy strategies for patients with severe ulcerative colitis flare-ups represent a significant clinical aspect. Several studies have identified a number of factors predictive for failed response to corticoids in patients with severe ulcerative colitis flares (more than 8 stools/day, persistent fecal blood, fever above $38^{\circ} \mathrm{C}$, albumin below $30 \mathrm{~g} / \mathrm{l}$, severe endoscopic lesions, CRP levels persisting above $45 \mathrm{mg} / \mathrm{l}$, and heart rate faster than $100 \mathrm{bpm}$ ), whose persistence on day 3 after therapy onset with steroids at full dosage very likely suggests refractoriness, and highlights a need for salvage therapy (4-7).

CyA modulates calcineurin phosphatase activity, which results in the nuclear suppression of transcription factors for various genes coding for proteins involved in inflammation, not only proinflammatory interleukins such as IL-2 but also other molecules including tumor necrosis factor alpha (TNF $\alpha)$ and gamma-interferon (8). However, its highly variable bioavailability among individuals, which depends on cytochrome P450 genetic polymorphisms, influences effectiveness to some extent, and requires that plasma levels be monitored (9). The best established indication of $\mathrm{CyA}$ for inflammatory bowel disease (IBD) is severe, corticoid-refractory flare-ups of ulcerative colitis $(10,11)$. Intravenous CyA has proven an effective salvage therapy for patients with severe UC flares. In the initial study by Litchiger 9 of 11 patients receiving CyA $4 \mathrm{mg} / \mathrm{kg}$ i.v. avoided colectomy versus none of 9 patients receiving placebo (12). Data from a second controlled trial confirmed that CyA ( $2 \mathrm{mg} / \mathrm{kg}$ i.v.) monotherapy is effective for remission induction in patients with severe UC flares, but not all patients were refractory to intravenous steroids (13). An overall analysis of results from both controlled and non-controlled studies assessing the effectiveness of CyA in these patients found a weighted mean of 76-85\% responses with avoidance of colectomy in the short term (14); however, after five years of follow-up only $50 \%$ of initial responders to this drug remained free from colectomy, and azathioprine-naïve patients were those who responded best (bridging strategy) $(15,16)$. 
Intravenous administration of CyA requires careful monitoring since toxicity, and possibly effectiveness depend on plasma levels, which should be measured every two days. Given that 4 and $2 \mathrm{mg} / \mathrm{kg}$ dosages have been demonstrated to be similarly effective, the latter is initially recommended, with subsequent titration based on measured plasma levels (17). Median time to a response to intravenous CyA is 4-5 days, and two therapy options are considered for responders - change to oral CyA combined with azathioprine or to azathioprine alone with no oral CyA bridge (18). Non-responders are eligible for colectomy. In this group of non-responders to CyA, salvage therapy with infliximab should only be performed in centers highly experienced with this strategy and the management of these patients (19). However, because of its side-effect profile CyA is considered a second-line therapy. In addition to renal and neural toxicity, opportunistic infections, some of them serious and life-threatening, have been described, and thus prophylaxis with trimethoprim-sulfamethoxazole is advisable for therapy regimens equal to or longer than 7 days, and using triple immunosuppression.

Following the above analysis, it is seemingly consistent to evaluate potential response-predicting factors that may help us select candidates most suited to this therapy. Recognition of factors predictive of response to CyA would be important, much in the same way as the aforementioned factors predictive for response to steroids during severe UC flares, which allow an early selection of those refractory patients who are eligible for second-line treatment (CyA, infliximab, surgery). In this respect, the study by Huamán-Rios et al. analyzed 41 flare-ups of corticoid-refractory UC in 35 patients in order to establish which early clinical and biological factors may discriminate non-responders to CyA (20). The authors concluded that older age ( $>40$ years), thrombocytosis, and prior cyclosporine use predict poor response to intravenous CyA during severe flare-ups of corticoid-refractory UC. Despite limitations brought about by the study's retrospective nature and lack of systematic colonoscopy for all patients involved, the availability of data that may help select patients at risk is in itself most significant. Studies with this same goal, one of them performed by Aceituno (21) in our country with two patient cohorts from two different centers, identify factors that tend to remain consistent, including CRP, hypoalbuminemia, and endoscopic lesions, parameters that behave as predictors for colectomy in patients receiving CyA $(22,23)$. Infliximab has proven effective in the treatment of severe, steroid-refractory flares, as demonstrated in a short Scandinavian series, where it significantly reduced the risk for colectomy at three months versus the placebo group, with around 50-60\% stabilizations after three years, these numbers being similar to those observed with CyA $(24,25)$. Neither salvage therapy option is well established as first-choice, but the subgroup of azathioprine-experienced patients is considered the one that would initially benefit from infliximab rescue (14). However, we should now wait for the results from a European study promoted by the French group GETAID, to which GETECCU contributes, comparing both therapy options, CyA versus infliximab, to analyze findings for effectiveness, which will undoubtedly help select the best treatment available.

In the meantime it is important that the timing of therapy for severe UC flares be adjusted, both to establish corticoid-refractoriness (3 days on intensive therapy, CRP, and presumably the Ho index) and to define factors predictive of poor response to CyA (Ho index, CRP $>45 \mathrm{mg} / \mathrm{dl}$, age $>40$ years, tachycardia), which will somehow help us consider other therapeutic alternatives. 


\section{References}

1. Truelove SC, Willoughby CP, Lee EG, Kettlewell MG. Further experience in the treatment of severe attacks of ulcerative colitis. Lancet 1978; 2: 1086-8.

2. Travis SP, Farrant JM, Ricketts C, Nolan DJ, Mortensen NM, Kettlewell MG, et al. Predicting outcome in severe ulcerative colitis. Gut 1996; 38: 905-10.

3. Edwards FC, Truelove SC. The course and prognosis of ulcerative colitis. Gut 1963; 4: 299-315.

4. Bernal I, Mañosa M, Domenech E, García-Planella, Navarro M, Cabré E, et al. Predictors of clinical response to systemic steroids in active ulcerative colitis. Dig Dis Sci 2006; 51: 1434-8.

5. Carbonnel F, Gargouri D, Lémann M, Beaugerie L, Cattan S, Cosnes J, et al. Predictive factors of outcome of intensive intravenous treatment for attacks of ulcerative colitis. Aliment Pharmacol Ther 2000; 14: 273-8.

6. Ho GT, Mowat C, Goddard CJ, Fennell JM, Shah NB, Prescott RJ, et al. Predictinig the outcome of severe ulcerative colitis: development of a novel risk score to aid early selection of patients for second-line medical therapy or surgery. Aliment Pharmacol Ther 2004; 19: 1079-87.

7. Ando T, Nishio Y, Watanabe O, Maeda O, Ishiguro K, Ishikawa D, et al. Value of colonoscopy for prediction of prognosis in patients with ulcerative colitis. World J Gastroenterol 2008; 14: 2133-8.

8. Hutchinson IV, Bagnall W, Bryce P, Pufong B, Geraghty P, Brogan I. Differences in the mode of action of cyclosporine and FK506. Transplant Proc 1998; 30: 959-60.

9. Hinojosa J. Farmacología de la enfermedad inflamatoria intestinal. En: Gassull MA, Gomollón F, Hinojosa J Obrador A, editores. Enfermedad Inflamatoria Intestinal. $3^{\mathrm{a}}$ ed. Madrid: Arán Ediciones S.L. 2007; p. 209-34.

10. García-López S, Gisbert JP, Gomollón F. Cyclosporine A in the treatment of severe attack of ulcerative colitis: A systematic review. Gastroenterol Hepatol 2005; 28: 607-14.

11. Shibolet O, Regushevskaya E, Brezis M, Soares-Weiser K. Cyclosporine A for induction of remission in severe ulcerative colitis. The Cochrane database of Systematic Reviews 2005, Issue 1. Art. No.:CD004277. pub2.

12. Lichtiger S, Present DH, Kornbluth A, Gelernt I, Bauer J, Galler G, et al. Cyclosporine in severe ulcerative colitis refractory to steroid therapy. N Engl J Med 1994; 330: 1841-5.

13. D'Haens G, Lemmens L, Geboes K, Vandeputte L, Van Acker F, Mortelmans L, et al. Intravenous cyclosporine versus intravenous corticosteroids as single therapy for severe attacks of ulcerative colitis. Gastroenterology 2001; 120: 1323-9.

14. an Assche G, Vermeire S, Rutgeerts P. Treatment of severe steroid refractory ulcerative colitis. World J Gastroenterol 2008; 14(36): 5508-11.

15. Arts J, D'Haens G, Zeegers M, Van Assche G, Hiele M, D'Hoore A, et al. Long- term outcome of treatment with intravenous cyclosporin in patients with severe ulcerative colitis. Inflamm Bowel Dis 2004; 10: 73-8A.

16. Moskovitz DN, Van Assche G, Maenhout B, Arts J, Ferrante M, Vermeire S, et al. Incidence of colectomy during long-term follow-up after cyclosporine-induced remission of severe ulcerative colitis. Clin Gastroenterol Hepatol 2006; 4: 760-5.

17. Van Assche G, D'Haens G, Noman M, Vermeire S, Hiele M, Asnong K, et al. Randomized, double-blind comparison of $4 \mathrm{mg} / \mathrm{kg}$ versus $2 \mathrm{mg} / \mathrm{kg}$ intravenous cyclosporine in severe ulcerative colitis. Gastroentero$\log 2003 ; 125: 1025-31$.

18. Doménech E, García-Planella E, Bernal I, Rosinach M, Cabré E, Fluviá L, et al. Azathioprine without oral ciclosporina in the long term maintenance of remission induced by intravenous ciclosporine in severe, steroidrefractory ulcerative colitis . Aliment Pharmacol Ther 2002; 16: 2061-5.

19. Maser E, Deconda D, Lichtiger S, Present D, Kornbluth A. Cyclosporine (CsA) and infliximab (Infl) as acute salvage therapies for each other in severe steroid refractory ulcerative colitis (UC). Gastroenterology 2007; 132: A180.

20. Huamán Ríos JW, Casellas Jordá F, Malagelada Benaprés JR. Predictive factors of poor response to intravenous cyclosporine in steroid-refractory ulcerative colitis. Rev Esp Enferm Dig 2009; 101(3): 163-71.

21. Aceituno M, García-Planella E, Heredia C, Zabana Y, Feu F, Domènech E, et al. Steroid-refractory ulcerative colitis: predictive factors of response to cyclosporine and validation in an independent cohort. Inflamm Bowel Dis 2008; 14: 347-52.

22. Cacheux W, Seksik P, Lemmann M, Marteau P, Nion-Larmurier I, Afchain P, et al. Predictive factors of response to cyclosporine in steroid-refractory ulcerative colitis. Am J Gastroenterol 2008; 103: 637-42.

23. Rowe FA, Walker JH, Karp LC, Vasiliauskas EA, Plevy SE, Targan SR. Factors predictive of response to cyclosporine treatment for severe, steroid-resistant ulcerative colitis. Am J Gastroenterol 2000; 95: 2000-8.

24. Actis G, Fadda M, David E, Sapino A. Colectomy rate in steroid-refractory colitis initially responsive to cyclosporine: a long-term retrospective cohort study. BMC Gastroenterology 2007; 7: 1-6.

25. Jarnerot G, Hertervig E, Friis-Liby I, Blomquist L, Karlén P, Grännö C, et al. Infliximab as rescue therapy in severe to moderately severe ulcerative colitis: a randomized, placebo-controlled study. Gastroenterology 2005; 128: 1805-11. 